\title{
ALGUMAS CONSIDERAÇÕES ACERCA DA IMPORTÂNCIA DE ÁREAS VERDES URBANAS, O CASO DE UBERABA (MG)
}

\author{
Juliana Paula da Silva Rodrigues ${ }^{1}$
}

\author{
Idelvone Mendes Ferreira ${ }^{2}$
}

\begin{abstract}
RESUMO
A migração das pessoas do campo para as cidades, associado ao pouco ou nenhum planejamento, possibilitou um crescimento urbano desordenado, com a ocupação de locais inapropriados, causando impactos ambientais urbanos, o que afeta a qualidade de vida das populações. O presente texto tem por objetivo apresentar uma reflexão acerca da importância das áreas verdes nas cidades e como estas influenciam na qualidade ambiental urbana. Assim, realizou-se uma análise das áreas verdes na cidade de Uberaba (MG). Para tal, inicialmente, realizou-se uma revisão bibliográfica referente aos seguintes temas: qualidade ambiental urbana, impactos ambientais urbanos, importância de áreas verdes, entre outros. A metodologia de análise foi pautada principalmente nos seguintes autores: Nucci (2001), Braga (2003), Borja (1997), entre outros. Foram realizadas análises de produtos cartográficos da cidade de Uberaba com o intuito de verificar as áreas verdes existentes e trabalhos de campo nos principais parques existentes na Cidade com o objetivo de avaliar as condições em que os mesmos se encontram. A partir das análises foi possível constatar a pouca quantidade de áreas verdes na Cidade e o descaso com os parques, o que afeta na qualidade ambiental urbana e, consequentemente, na qualidade de vida da população humana.
\end{abstract}

PALAVRAS-CHAVE: qualidade ambiental urbana. áreas verdes. Uberaba (MG)

\section{SOME CONSIDERATIONS ABOUT THE IMPORTANCE OF URBAN GREEN AREAS, THE CASE OF UBERABA (MG)}

\section{ABSTRACT}

The migration of people from rural areas to cities, coupled with little or no planning, allowed an urban sprawl, with the occupation of inappropriate places, causing urban environmental impacts, which affects the quality of

\footnotetext{
1 Mestranda, Programa de Pós-Graduação em Geografia da Universidade Federal de Goiás Regional Catalão; Núcleo de Estudos e Pesquisas Socioambientais - NEPSA/CNPq. julianna_paula@hotmail.com

2 Professor do Programa de Pós-Graduação em Geografia da Universidade Federal de Goiás Regional Catalão; Coordenador do Núcleo de Estudos e Pesquisas Socioambientais -NEPSA/CNPq. idelvoneufg@gmail.com
} 
life. This paper aims to present a reflection on the importance of green areas in cities and how this influences the urban environmental quality. Thus, we performed an analysis of the green areas in the city of Uberaba (MG). For this purpose, initially conducted a literature review covering the following themes: urban environmental quality, urban environmental impacts, importance of green areas, among others. In general, the method of analysis was based on the following authors: Nucci (2001), Braga (2003), Borja (1997). Analysis of cartographic products of the city of Uberaba in order to verify the existing green areas were performed. And work camps in the main parks in the city with the aim of evaluating the conditions in which they find themselves. From our analysis, we determined how few green areas in the city and the neglect of the parks, which affects the urban environmental quality and therefore the quality of life of the human population.

\section{UNAS PALABRAS SOBRE LA IMPORTANCIA DE LAS ZONAS VERDES URBANAS, EL CASO DE UBERABA (MG)}

\section{RESUMEN}

La migración de personas de las zonas rurales a las ciudades, junto con poca o ninguna planificación, permitió una expansión urbana, con la ocupación de lugares inapropiados, causando impactos ambientales urbanas, lo que afecta la calidad de vida. Este trabajo tiene como objetivo presentar una reflexión sobre la importancia de las zonas verdes en las ciudades y cómo esto influye en la calidad del medio ambiente urbano. Por lo tanto, se realizó un análisis de las áreas verdes en la ciudad de Uberaba (MG). Para ello, inicialmente llevado a cabo una revisión de la literatura sobre los siguientes temas: calidad del medio ambiente urbano, impactos ambientales urbanas, importancia de las zonas verdes, entre otros. En general, el método de análisis se basa en los siguientes autores: Nucci (2001), Braga (2003), Borja (1997). Se llevaron a cabo análisis de los productos cartográficos de la ciudad de Uberaba, a fin de verificar las áreas verdes existentes. Y los campos de trabajo en los principales parques de la ciudad con el objetivo de evaluar las condiciones en que se encuentran. De nuestro análisis, determinamos cómo pocas zonas verdes de la ciudad y el descuido de los parques, lo que afecta la calidad del medio ambiente urbano y por lo tanto la calidad de vida de la población humana.

PALABRAS-CLAVE: calidad del medio ambiente urbano. zonas verdes. Uberaba (MG)

\section{1- INTRODUÇÃO}

Cada vez mais, nos estudos ambientais, estão sendo realizadas pesquisas com o intuito de possibilitar um desenvolvimento humano com uso dos recursos naturais, mas sem que haja uma perda destes, ou seja, uma análise do que pode ser utilizado e do que deve ser preservado. Um dos ramos das pesquisas ambientais que tem se destacado são os estudos ambientais em áreas urbanas. Uma vez que, com o aumento da migração de pessoas do campo para as cidades, associado ao pouco ou nenhum planejamento, tem-se como consequência um 


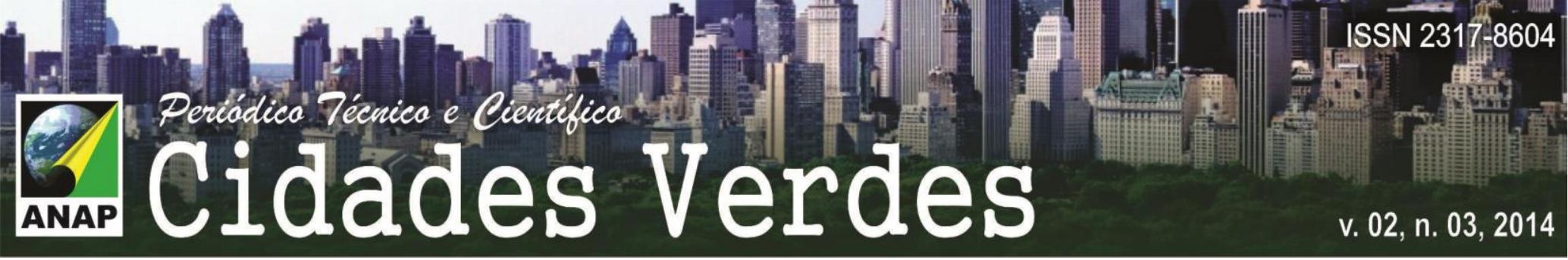

crescimento urbano desordenado, com a ocupação de locais inapropriados, causando impactos ambientais urbanos posteriormente.

As transformações que ocorrem no território nacional, principalmente aquelas decorrentes dos anos da década de 1980, em função do aumento da migração rural urbana, constituíram-se nos principais elementos transformadores das paisagens. Entre os reflexos dessas transformações está o intenso crescimento das taxas de urbanização do País.

O rápido e desordenado crescimento urbano e o grande incremento populacional humano pressionou de tal forma o meio físico que vários processos estão desencadeando reações danosas aos meios nos quais estão inseridas as cidades, e que acaba por influenciar na qualidade de vida da população humana.

Nesse contexto, uma das análises que constitui um importante subsídio ao planejamento é a avaliação da qualidade ambiental urbana, pois permite o levantamento de dados que podem ser utilizados na análise do espaço das cidades e na melhoria da qualidade de vida da população humana.

Com base no que foi exposto, o presente texto tem por objetivo apresentar uma reflexão acerca da importância das áreas verdes nas cidades e como estas influenciam na qualidade ambiental urbana. Assim, realizou-se uma análise das áreas verdes em Uberaba (MG), Cidade esta que teve a sua ocupação e expansão no entorno do Córrego das Lajes e que tem sofrido diversos impactos ambientais urbanos provenientes de sua formação e expansão sem o devido planejamento.

\section{DESENVOLVIMENTO}

Para essa discussão, inicialmente, considera-se fundamental uma breve exposição sobre a qualidade ambiental urbana. Este tipo de estudo tem se desenvolvido durante todo o Século XX, sobretudo após as décadas 1970- 80, tendo expressividade os trabalhos de Lombardo (1985), Monteiro (1987), Troppmair (1989), Cavaleiro (1991; 1992), Borja (1997) e, mais recentemente, Nucci (2001), com diversos focos para a temática. Porém, conforme afirma Nucci (2001), ainda são poucos os trabalhos referentes ao tema e, consequentemente, tem-se um 


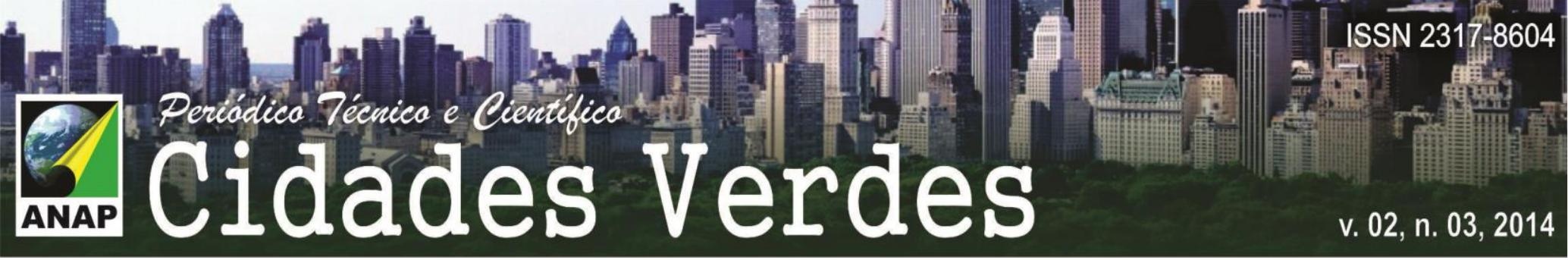

escasso rol de possibilidades metodológicas para a abordagem do ambiente urbanizado. Conforme aponta Monteiro (1987 apud NUCCI, 2008, p. 2) "Executar um trabalho de espacialização da qualidade ambiental constitui um verdadeiro desafio, visto que não existe uma receita técnica calcada numa concepção teóricometodológica pronta".

Assim, diferentes autores discutem a qualidade ambiental urbana com focos diversos. Segundo Borja (1997), uma proposta de metodologia sobre a qualidade ambiental, deve integrar os diversos níveis de conhecimento da realidade, contemplando três planos de investigação: o científico, o técnico e o cultural ou comunitário.

Conforme afirma Minaki e Amorin (2008) o conceito de qualidade ambiental, que apresenta maior visibilidade principalmente após o surgimento da sociedade moderna, integra um conceito maior definido como qualidade de vida. Este, por sua vez, é um diagnóstico da existência ou não de condições saudáveis de habitação, em termos humanos, sociais, ecológico-ambientais, econômicos, dentre outros, obtidos em conjunto num determinado local.

Em relação à análise da qualidade ambiental, segundo estudos realizados por Braga (2003), o sistema de índices de sustentabilidade municipal é composto por quatro índices temáticos: 1) qualidade do sistema ambiental local; 2) qualidade de vida humana; 3) pressão antrópica; 4) capacidade política e institucional. Combinados, os quatro índices buscam mensurar a sustentabilidade municipal. $O$ índice de qualidade do sistema ambiental mensura o grau de saúde do sistema ambiental do município. O índice de qualidade de vida humana mensura a capacidade do município em reduzir a desigualdade social, prover os habitantes de condições básicas de vida e prover seus habitantes de um ambiente construído saudável e seguro. O índice de pressão antrópica mensura o potencial de degradação e o grau de impacto antrópico no município. O índice de capacidade político institucional mensura a robustez política e institucional para o enfrentamento de desafios presentes e futuros. Portanto, "[...] entende-se, assim, que a qualidade do ambiente é uma parte fundamental da qualidade de vida humana que abrange outros fatores, como os sócio-econômicos, existências, etc." (NUCCI, 2008, p. 11). 


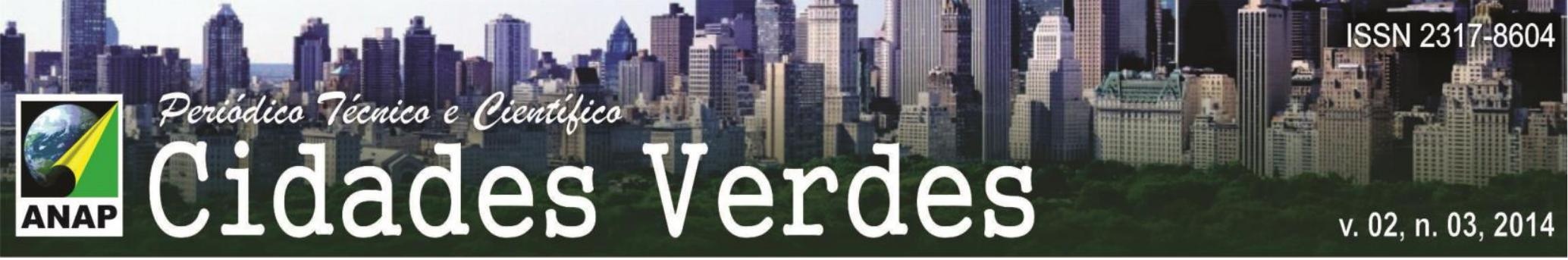

Assim, Nucci (2001) propõe o estudo da qualidade ambiental a partir da consideração dos seguintes parâmetros como uso do solo, poluição, enchentes, densidade populacional (humana), verticalidade das edificações, desertos florísticos e déficit de espaços livres para lazer, espacializados e integrados em escala que variam entre 1:2000 e 1:10.000. Este método tem como base geral os estudos relacionados com a Ecologia e Planejamento da Paisagem, que pode ser entendido como uma contribuição ecológica para o planejamento do espaço, com o intuito de regulamentar os usos do solo e dos recursos ambientais, preservando a capacidade dos ecossistemas e o potencial recreativo da paisagem, extraindo-se maior proveito que a vegetação pode fornecer para a melhoria da qualidade ambiental.

A partir da metodologia proposta por Nucci (2008), com base no Planejamento da Paisagem, a vegetação ganha destaque, pois a partir dela muitos problemas seriam amenizados ou resolvidos, assim a mesma proveria subsídios importantes na melhoria da qualidade ambiental. Segundo o autor:

\begin{abstract}
Dentro da linha metodológica do Planejamento da Paisagem, quando se fala em planejar com a natureza, está se falando principalmente da vegetação. É a partir dela que muitos problemas serão amenizados ou resolvidos e, portanto, a cobertura vegetal, tanto em termo qualitativo como quantitativo e também sua distribuição espacial no ambiente urbano, deve ser cuidadosamente considerada na avaliação da qualidade ambiental." (NUCCl, 2008, p. 24)
\end{abstract}

Ainda, Nucci (2008) apresenta, com base em vários autores, os benefícios que as áreas verdes podem trazer ao ser humano das cidades, tais como: estabilizam de forma significativa as superfícies por meio da fixação do solo com a ação das raízes das plantas; criam obstáculos contra o vento; protegem a qualidade da água; filtram o ar; diminuem a poeira em suspensão; equilibram os índices de umidade no ar; reduzem o barulho; servem de abrigo para a fauna; contribuem para a organização e composição de espaço no desenvolvimento das atividades humanas; e atenuam o impacto pluvial auxiliando na captação de águas pluviais, uma vez que a impermeabilização crescente prejudica a infiltração.

Assim, por todas as funções que a vegetação é capaz de realizar na cidade, seria interessante que se incentivassem todas as possiblidades de aumento da cobertura vegetal nas áreas urbanizadas, pois a diminuição destas altera suas 


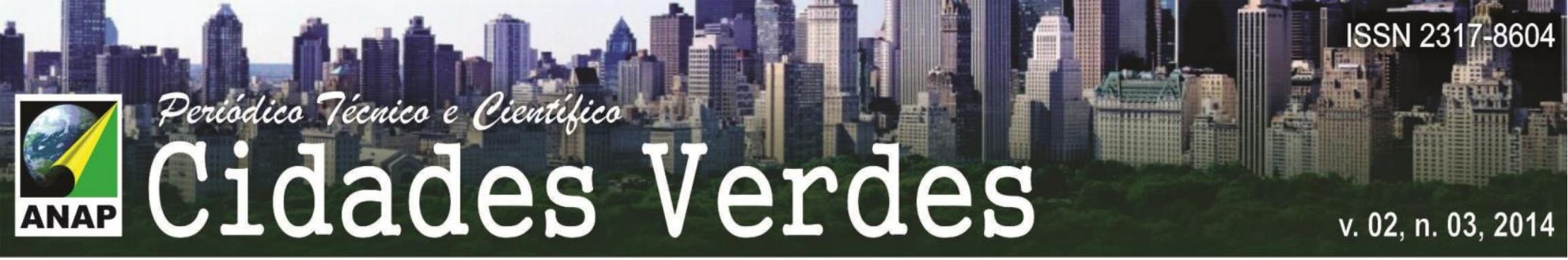

árvores das vias públicas, desde que exerça as funções de uma área verde), com solo livre de edificações ou coberturas impermeabilizantes (em pelo menos $70 \%$ da área), de acesso público ou não, e que exerçam minimamente as funções ecológicas (aumento do conforto térmico, controle da poluição do ar e acústica, interceptação das águas das chuvas, e abrigo à fauna), estéticas (valorização visual e ornamental do ambiente e diversificação da paisagem construída) e de lazer (recreação).

Observando-se a Figura 1, sobre a disposição de áreas verdes e áreas institucionais da Secretaria Municipal de Infraestrutura de Uberaba, é possível constatar a pouca quantidade de áreas verdes existentes na Cidade.

Figura 1- Disposição de áreas verdes e áreas institucionais vinculados a Secretaria Municipal de Infraestrutura de Uberaba (MG)

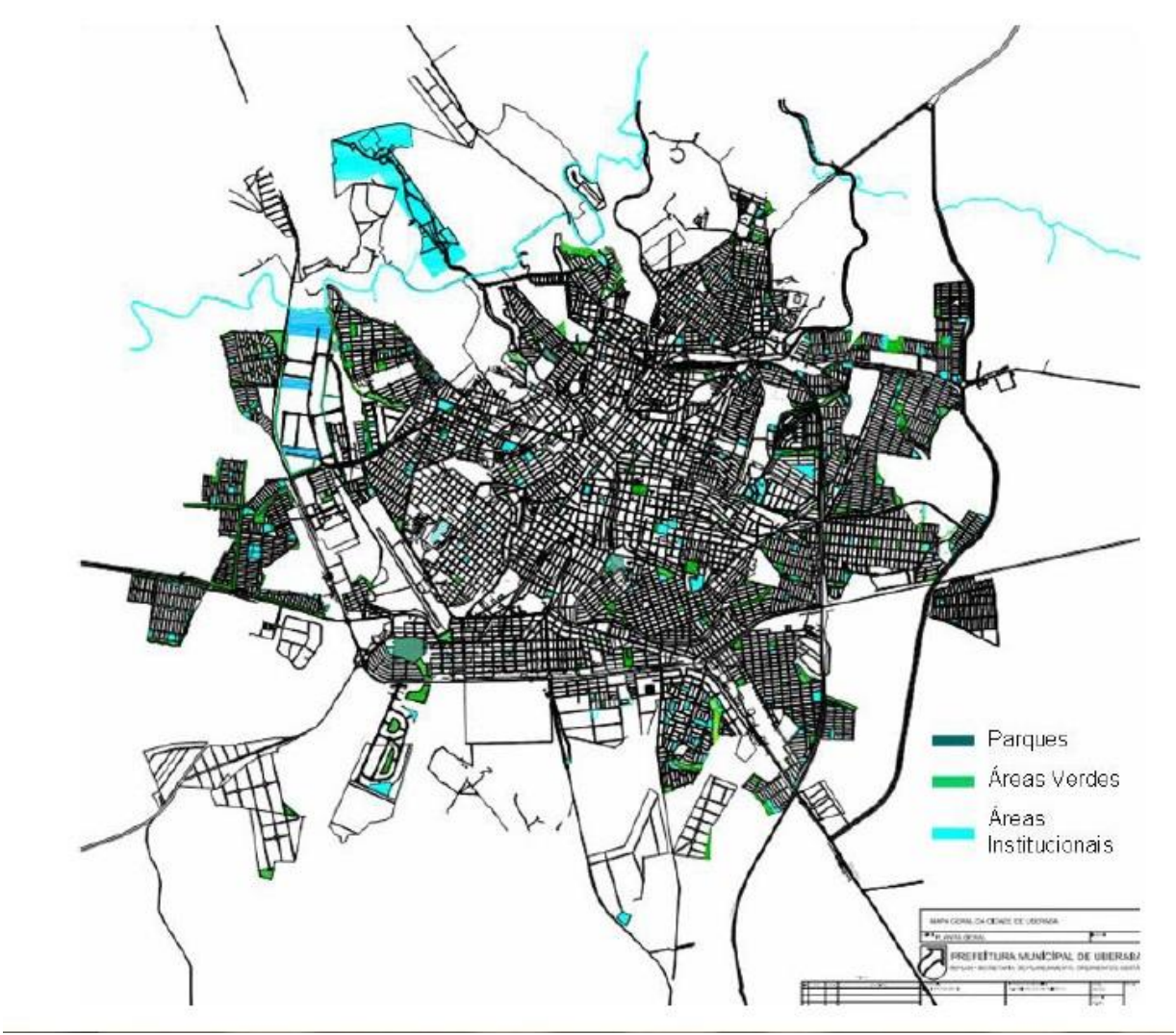

Fonte: PMU apud Souza 2004 


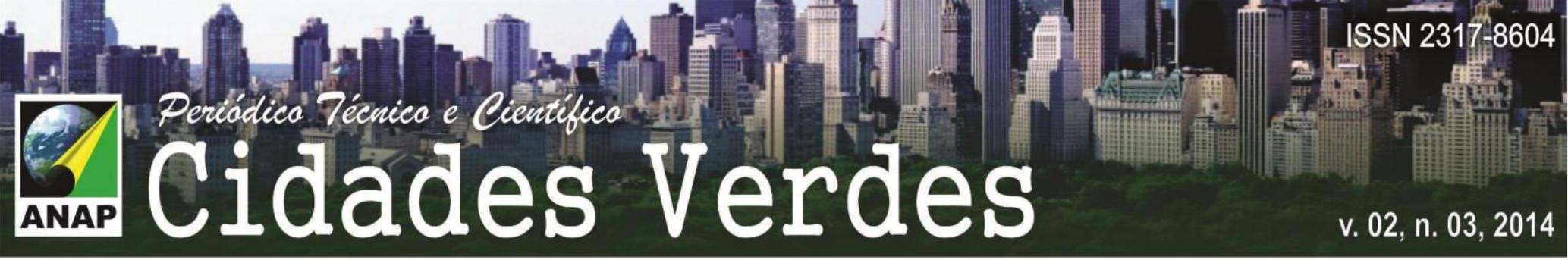

A partir do que foi exposto, optou-se por realizar uma análise das atuais condições em que se encontram os parques da cidade de Uberaba (MG). Assim, discorrer-se-á sobre os Parques Jacarandá, Mata do Ipê e Mata do Carrinho.

A área do Parque da Mata do Carrinho encontra-se localizada no bairro Volta Grande (coordenadas $19^{\circ} 46^{\prime} 26^{\prime \prime}$ S; $47^{\circ} 57^{\prime} 53^{\prime \prime}$ W), e começou a ser reconhecida como patrimônio da Cidade por meio do Decreto Municipal no 0381, de 4 de junho de 1985, e neste mesmo ano, a área passou a ser chamada de Parque Municipal "Mata do Carrinho". Possui uma área de 13, 26 há, estado aproximadamente $90 \%$ da área ocupada por fitofisionomias de Floresta Estacional Semidecídua (PEGORARI, 2007).

O Parque encontra-se todo cercado por alambrados com a presença de trilhas que atravessam as áreas vegetacionadas. Há as edificações administrativas na entrada do Parque separada da área de floresta, bem como a quadra de esportes e, logo na entrada do Parque, está o Orquidário Municipal. Tem-se ainda várias nascentes perenes que alimentam o curso d'água responsável pela formação de áreas brejosas no Parque.

Ao adentrar no Parque, o que mais chama atenção é o abandono do mesmo. Nas edificações administrativas não há funcionários recebendo os visitantes e a própria edificações encontram-se descuidadas, com janelas quebradas, como se pode observar na Figura 2.

Figura 2- Instalações físicas do Parque com estruturas descuidadas. No detalhe, janela de vidro quebrada.

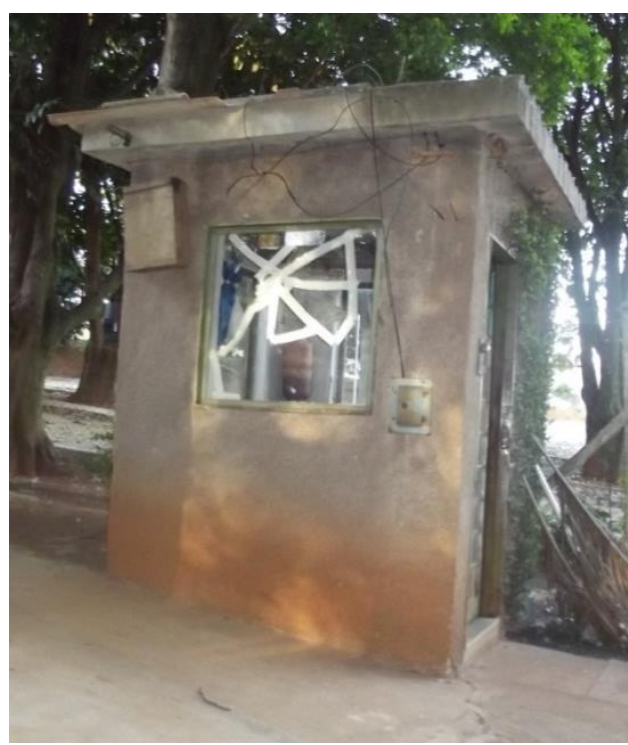

Fonte: RODRIGUES, J. P. da S. (JUNHO/2014) 


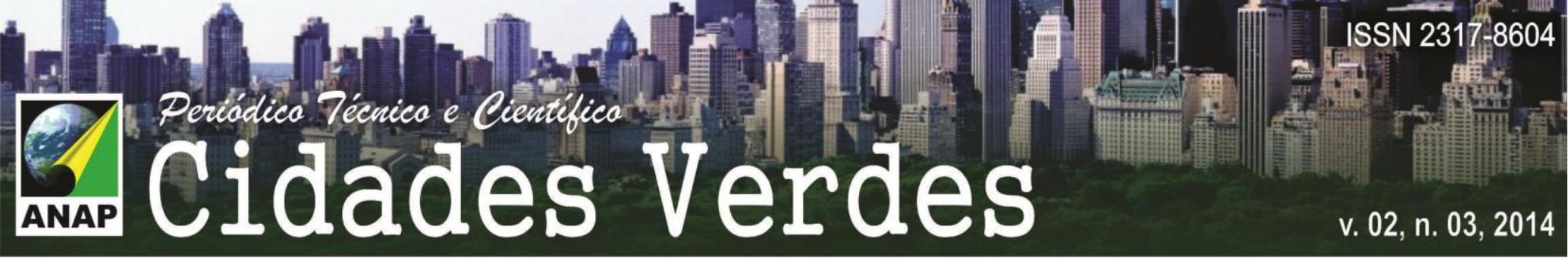

Os sanitários também se encontram em estado de má conservação, como a falta de iluminação e limpeza. Os equipamentos de recreação existentes no parque, como a quadra e o playground, também encontram-se abandonados. Os poucos bancos existentes são de troncos de madeiras e encontram-se também estragados (Figura 3). As trilhas estão mal sinalizadas e são de difícil acessibilidade.

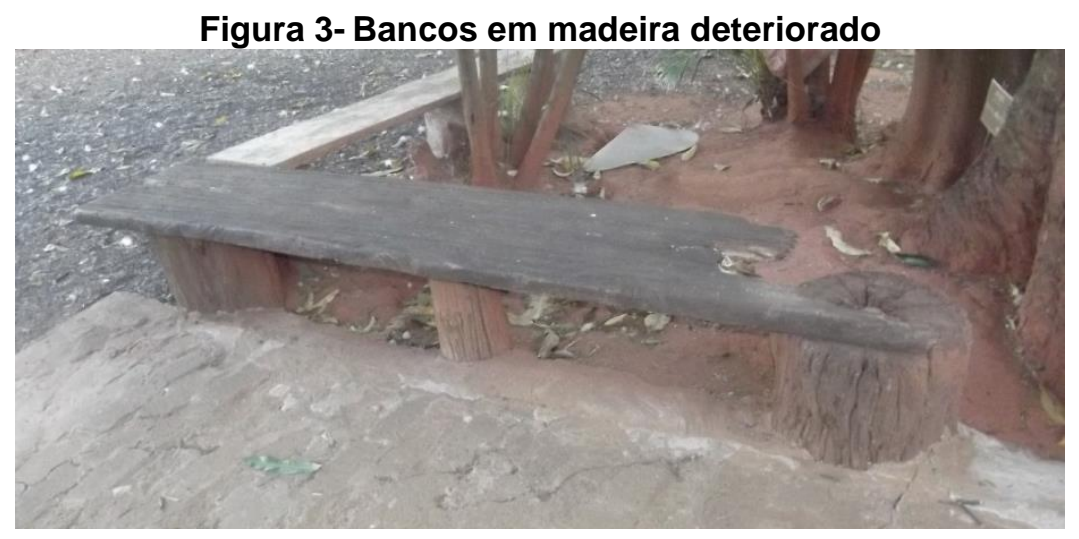

Fonte: RODRIGUES, J. P. da S. (JUNHO/2014)

O Orquidário Municipal, localizado no Parque, encontra-se abandonado com as várias espécies mortas (Figura 4).

Figura 4- Orquidário do Parque com espécies vegetais mortas

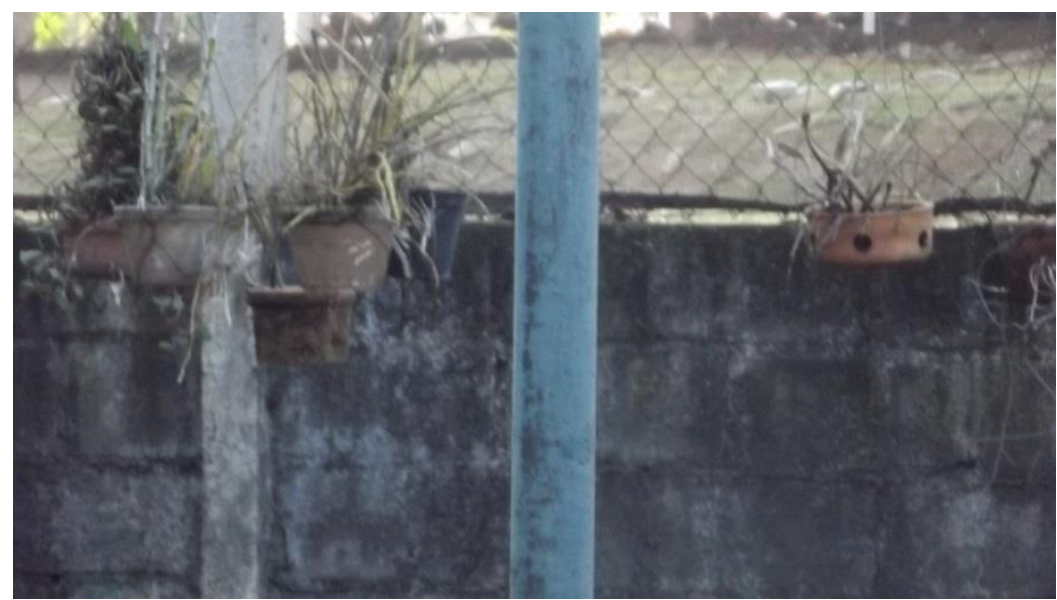

Fonte: RODRIGUES, J. P. da S. (JUNHO/2014)

$\mathrm{Na}$ área florestada do Parque tem-se grande quantidade de árvores que foram cortadas e outras derrubadas. Outro problema que se pode observar nessa 


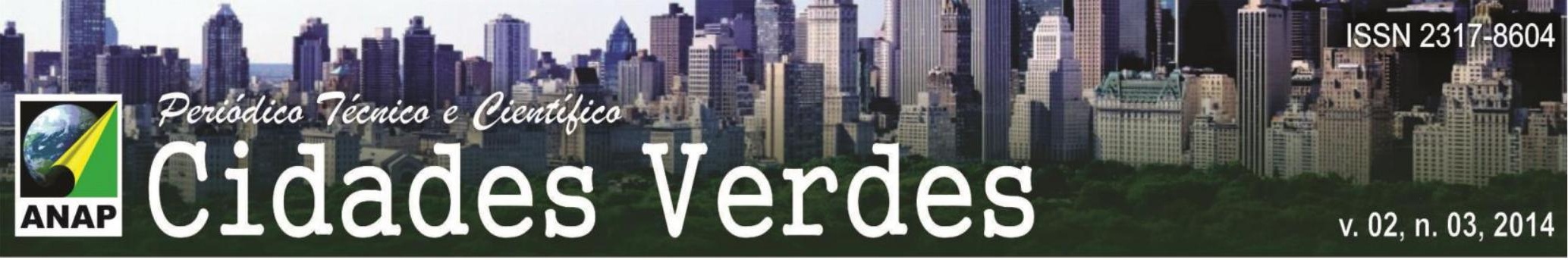

área do Parque é a presença de plantas exóticas, pois a invasão de plantas concorrentes é uma das principais causas de desequilíbrio ambiental, pois causam danos as espécies nativas, levando-as até mesmo a extinção.

No Parque tem-se ainda processos erosivos que estão presentes principalmente nas trilhas e na via de circulação que separa a porção leste e oeste do Parque (Figura 5). As Erosões são em decorrência do fluxo de água pluvial, inicialmente do tipo ravinamento que, sem o devido tratamento de contenção, a tendência é que o canal se aprofunda devido ao fluxo de água das enxurradas, transformando-se em sulcos de erosão. Há uma grande área caracterizada como solo exposto, o que pode ocasionar o aparecimento de novos processos erosivos. $E$ há áreas onde a grama foi plantada sem o devido cuidado/manejo.

Figura 5-Processo erosivo nas trilhas existentes no interior do Parque Mata do Carrinho

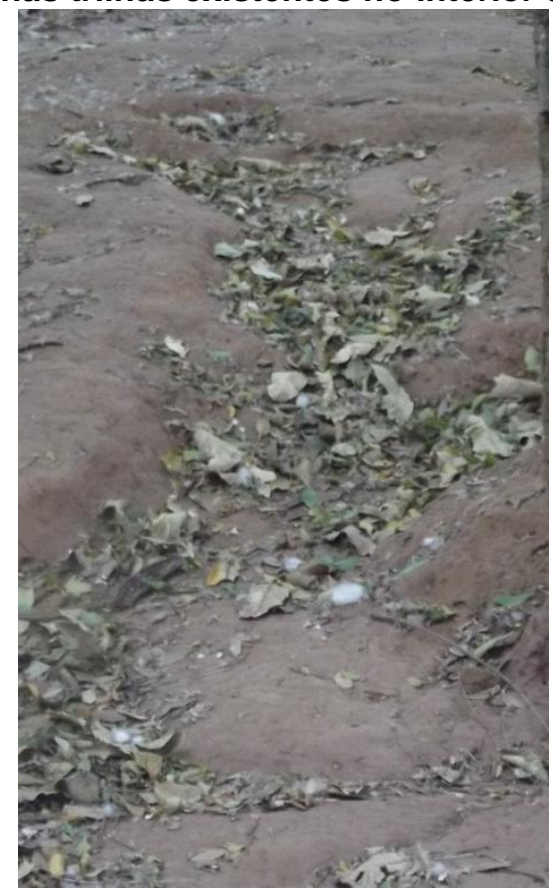

Fonte: RODRIGUES, J. P. da S. (JUNHO/2014)

Com relação ao Parque Mata do Carrinho, pode-se deduzir que falta atenção do Poder Publico Municipal quando a sua manutenção e proteção, principalmente quanto aos tratos e manejos para sua conservação.

O Parque Jacarandá, localizado na Vila Militar (coordenadas 19 44' 04" S; $47^{\circ} 56$ ' 36" W), foi definido como Bosque da Cidade pela Lei Municipal n 1423 , de 


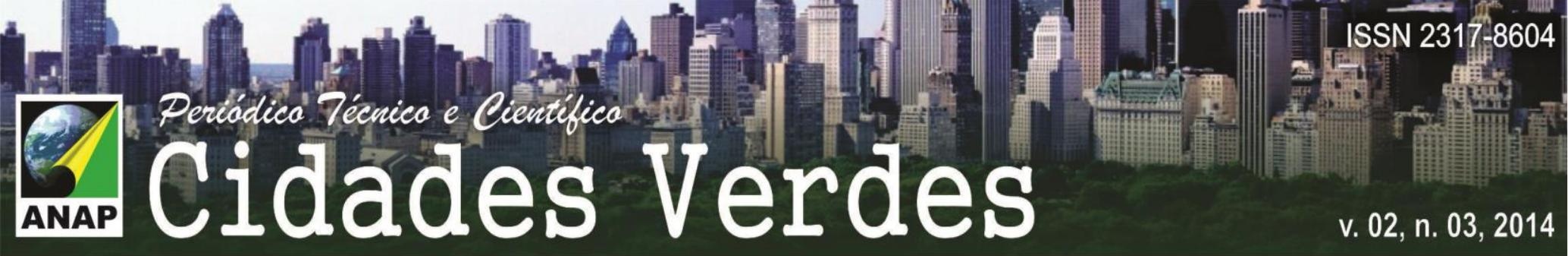

16 de fevereiro de 1966, e está encontra sob a administração da Prefeitura Municipal de Uberaba desde 1991. Possui uma área de 3,33ha, estando em sua maior parte ocupada por uma fitofisionomia de Floresta Estacional Semidecídua, com árvores atingindo até $30 \mathrm{~m}$ de altura. O local é cercado por muros e, em alguns pontos, por calçadas de cimento com 2 a $3 \mathrm{~m}$ de largura, delimitando espaços onde a vegetação é mantida. O Bosque abriga ainda um pequeno Zoológico (PEGORARI, 2007).

O Parque passou por uma reforma após a ameaça de ser desativado para a implantação de um Shopping center, possibilidade que foi descartada após a mobilização da população da Cidade. Assim, o mesmo teve mudanças que melhoraram a sua conservação, mas ainda há alguns problemas. $\mathrm{Na}$ área de vegetação mata tem-se a presença de espécies nativas e exóticas, o que pode comprometer as espécies nativas. Há a presença de clareiras e árvores mortas, e ainda áreas com solo exposto e compactado o que pode ocasionar o aparecimento de processos erosivos (Figura 6). Em algumas áreas foi possível observar o descuido, referente à limpeza e manutenção, o que compromete o valor estético do Parque (Figura 7).

Figura 6-- Área com solo exposto no Parque Jacarandá

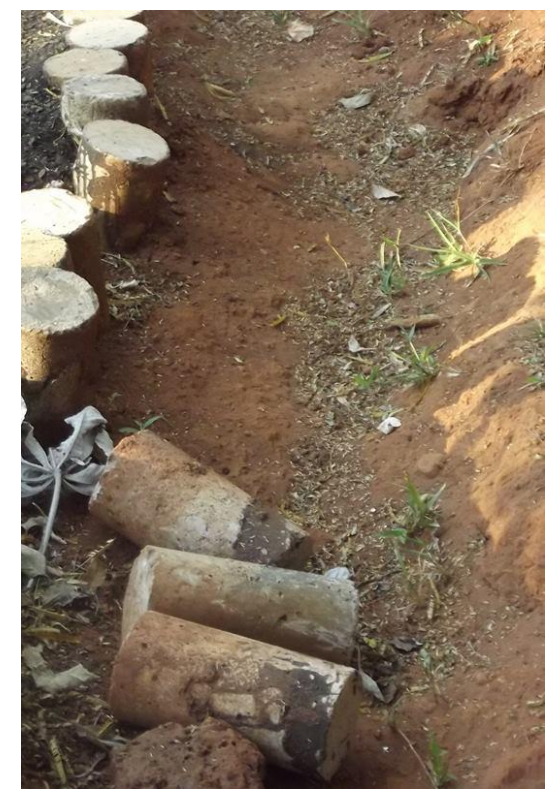

Fonte: RODRIGUES, J. P. da S.(JUNHO/2014) 


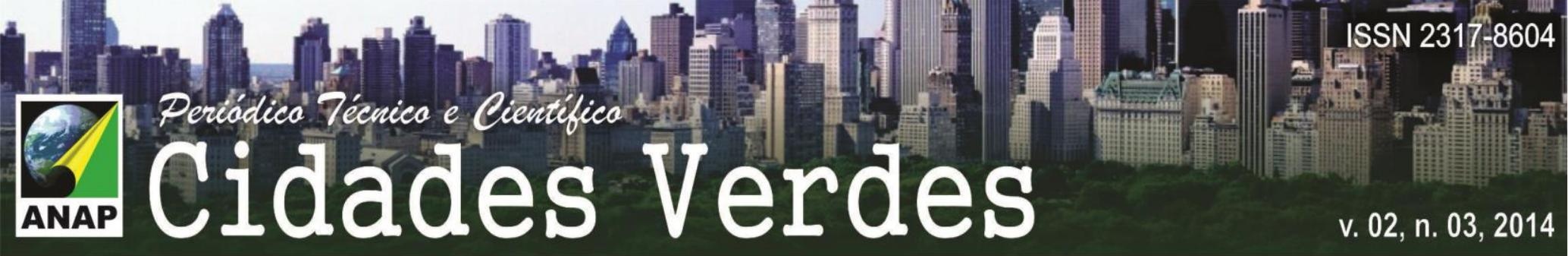

Figura 7- Área sem a devida limpeza

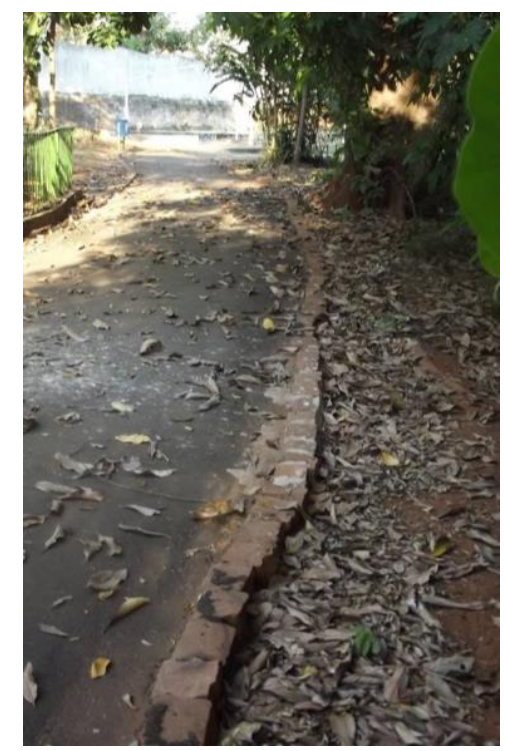

Fonte: RODRIGUES, J. P. da S. (JUNHO/2014)

Como pode-se observar, o Parque Jacarandá necessita de cuidados por parte da Administração Pública, visando sua conservação e preservação ambiental.

O Parque Mata do Ipê situa-se na área central da Cidade (coordenadas 19응 45' 45" S; 470 56' 00" W), originalmente criado pela Lei Municipal $n^{\circ} 2.593$, de 20 de abril de 1976, e transformado em Parque Municipal pela Lei 6.599, de 27 de março de 1998. Possui uma área de 3,53 ha e cerca de 85 \% é ocupada por fitofisionomias de Floresta Estacional Semidecídua. O Parque possui uma praça com guarita e edificações administrativas e um lago artificial. Ainda, na área do Parque existe um lago natural, formado pelas águas oriundas de quatro nascentes, duas internas e duas externas ao Parque (PEGORARI, 2007).

A área do Parque Mata do Ipê passou por uma revitalização no ano passado, porém há ainda alguns problemas em sua conservação. A área de mata do Parque é formada por espécies nativas e por espécies exóticas, o que pode comprometer as espécies nativas. Tem-se também a presença de clareiras nas fitofisionomias, número elevado de árvores mortas e compactação do solo em algumas áreas (Figura 8). 


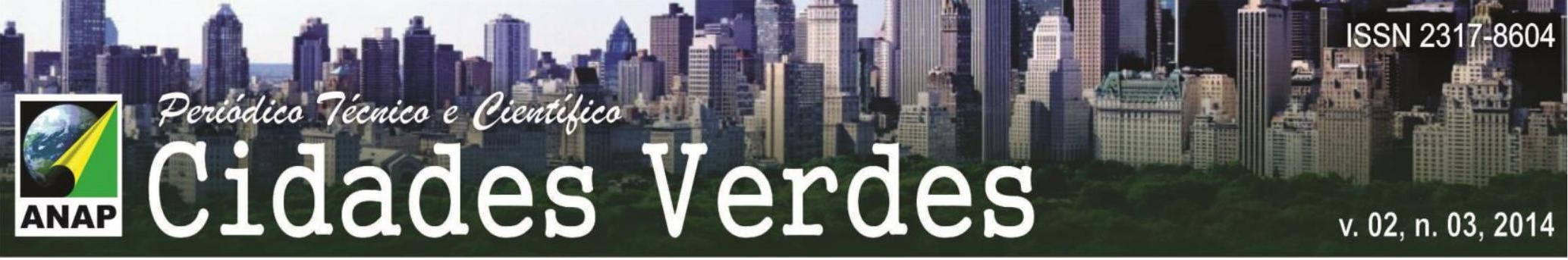

Figura 8-Mostra árvores mortas no interior doParque Mata do Ipê, Uberaba (MG)

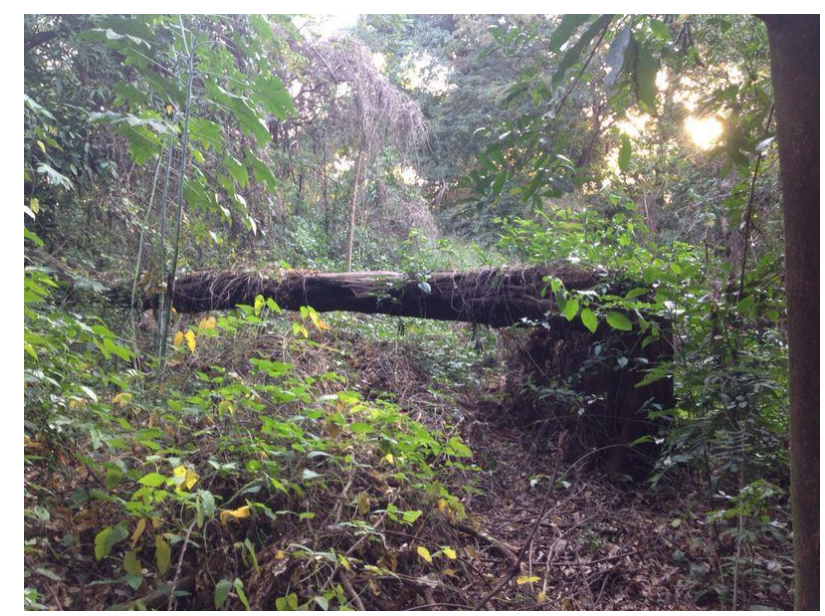

Fonte: RODRIGUES, J. P. da S. (JUNHO/2014)

Devido à degradação solo em algumas áreas, associado à drenagem pluvial do entorno, tem-se o aparecimento de processos erosivos. A drenagem pluvial no entorno do Parque, principalmente Bairros Abadia, Parque São Geraldo e Leblon, está direcionada para o Parque, trazendo consigo lixos e provocando o surgimento de diversos processos erosivos, desde sulcos até ravinamentos (Figura 9).

Figura 9-ravinamento no parque

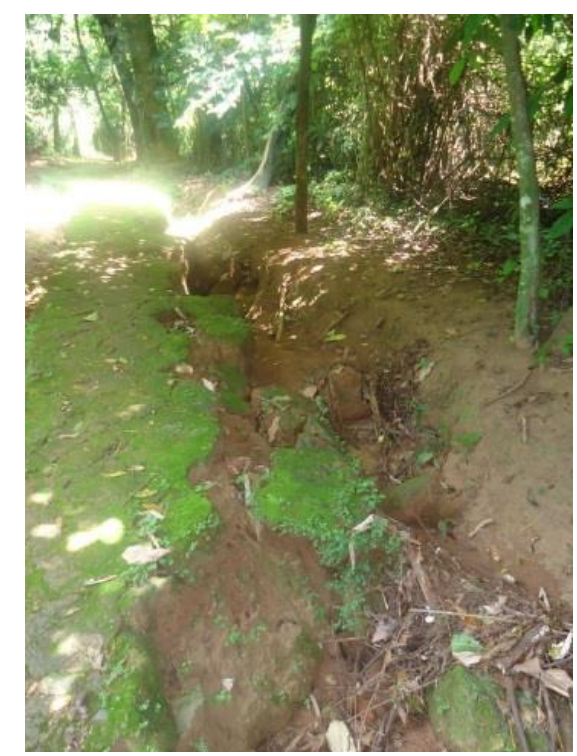

Fonte: RODRIGUES, J. P. S. (2014) 


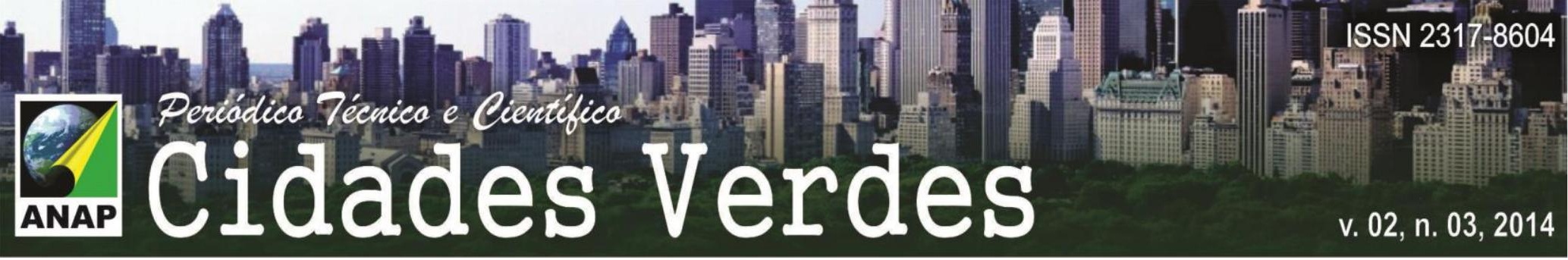

Nos lagos existentes na área do Parque Mata do Ipê foram identificadas a presença de algas evidenciando a eutrofização e possível contaminação das águas, bem como processos de contaminação associados ao lixo carreados pelo escoamento pluvial (Figura 10).

Figura 10- Mostra a área com lagoas artificiais existentes no Parque do Ipê, Uberaba (MG)

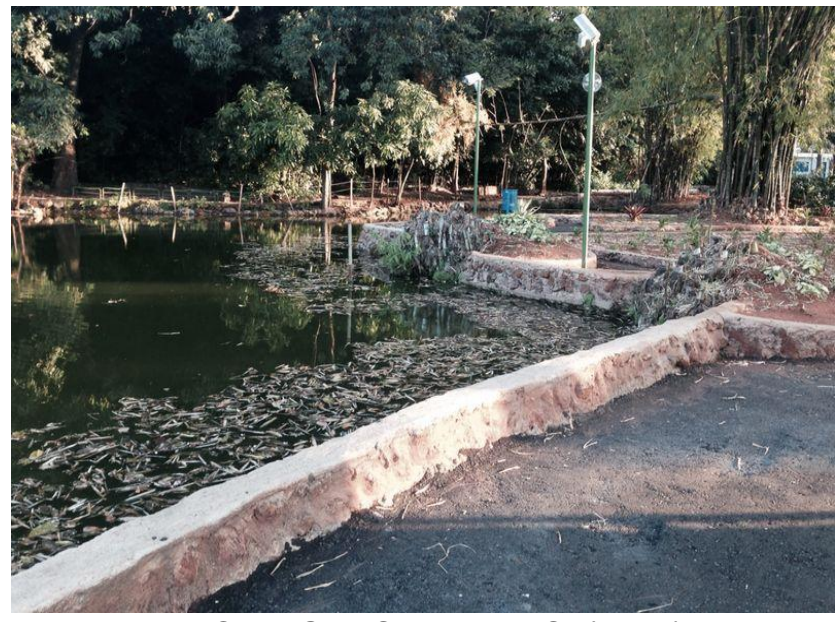

Fonte: RODRIGUES, J. P. da S. (2014)

Conforme o visualizado, a área do Parque Mata do Ipê, no perímetro urbano da cidade de Uberaba necessita urgentemente de melhor gestão por parte da Administração Municipal, visando sua conservação e preservação, enquanto unidade de conservação ambiental.

\section{3- CONCLUSÃO}

$\mathrm{Na}$ cidade de Uberaba (MG) foi possível constatar a pouca quantidade de áreas verdes e parques urbanos. Os parques existentes, em sua maioria, encontram-se em estado de abandono por parte do Poder Público Municipal.

A atual situação em que se encontram esses Parques acaba por interferir na qualidade ambiental urbana, consequentemente na qualidade de vida da população humana e demais biota, uma vez que estes são considerados como indicadores, pois a ausência deles interfere na qualidade do ambiente afetando a vida da população humana e suas correlações socioambientais. 
